International Journal of Current Research in Medical Sciences

ISSN: 2454-5716

DARSHAN

PUBLISHERS

WWW.ijcrims.com

Volume 2, Issue 9 -2016

DOI: http://dx.doi.org/10.22192/ijcrms.2016.02.09.002

\title{
Modulation of macromolecular damages and membrane structural integrity by Selenium in Radiation treated human stage (III) oral cancer cases
}

\author{
Sonaa Elango ${ }^{1}$, Zenith Khashim², Shila Samuel ${ }^{3}$, Usha Subbiah ${ }^{4}$, \\ Marie Carmel Balcos ${ }^{5}$
}

1.Department of Life Science, School of Natural Sciences, University of Suwon ,312, Wau-ri, Bongdam-eup,

Hwaseong-si, Gyeonggi-do ,445-743, Republic of Korea.

2. Department of Biotechnology, University of Madras, Chennai, India.

3. Department of Biochemistry, VRR Institute of BioMedical Sciences, University of Madras,

Kattupakkam, Chennai, India

4. Human Genetics Laboratory, Central Research Facility, Sree Balaji Dental College and

Hospital and Sree Balaji Medical College and Hospital, Barath University, Chennai, India.

5. Department of Bioscience and Biotechnology, University of Suwon, 17 Wauan-gil,

Bongdam-eup, Hwaseong-si, Gyeonggi-do, Republic of Korea.

Corresponding Author: Prof. Sonaa Elango Ph.D.,

E-mail: chonaa_2004@yahoo.co.in/sonaacumed@rediffmail.com

\section{Abstract}

Background: Selenium as an antioxidant minimize the macromolecular damages and the interrelation between the deteriorative effect of free radicals on membrane structural integrity in the blood of oral squamous cell carcinoma (OSCC) patients. Objective: 'Oxidative stress' implicated in oral carcinogenesis gets aggravated during radiation treatment. Selenium serves as a vital cofactor for glutathione peroxidase and is well known for its free radical-quenching effect. Materials and Methods: Study comprised of Group I (normal), Group II( untreated oral cancer patients), Group IIa (radiation treated) and Group IIb (radiation treated + selenium supplemented). Result: Increased degree of free radical content, lipid peroxidation, protein oxidation, DNA single strand scissions and DNA-protein cross link levels were observed in cancer and radiation treated cases. Selenium supplementation decreased all of these macromolecular damages and the incidence of apoptosis. The erythrocyte membrane showed a marked decrease in the activities of $\mathrm{Na}^{+}, \mathrm{K}^{+}$, $\mathrm{Ca}^{2+}, \mathrm{Mg}^{2+}$ ATPases in oral cancer and radiation group patients were found to be enhanced in their activities following selenium supplementation. Conclusion: Our observations highlight the protective effect of selenium in cancer and radiotherapy associated oxidative stress on the normal cells and the activities of membrane bound ATPases, thus proving selenium as a potent antioxidant.

Keywords: Selenium, ATPases, Lipid peroxidation, Membrane-bound enzymes, Oral cancer, radiotherapy.

\section{Introduction}

The interaction of ionizing radiation with biological matter generate a variety of molecular lesions that occur in essentially every organelle or sub compartment of the cell (1) Radiation produces 3 major classes of structural changes in DNA: a) DNA-protein crosslinks; b) Breaks in the DNA sugar-phosphate backbone ; c) Alterations in sugar and alterations like base loss; base damage. 
Int. J. Curr. Res. Med. Sci. (2016). 2(9): 8-21

Free radicals formed in close proximity with nucleic acids induce structural changes through formation of covalent bond adduct with normal host DNA. This results in DNA strand breaks, leading to misreading of DNA bases formation of micronuclei, damage to histones, aberrant signal transduction(2).

Cellular membranes are the second important radiation target in the cells. Radiation damage to membranes may impair important cellular functions such as the regulation of permeability, intracellular compartmentalization, and intercellular communication(3). Abundant reactive oxygen species (ROS) generation ultimately degrade the poly unsaturated fatty acids of the biomembrane(1).

Selenium, an essential nutrient, has been into focus by many researchers as a natural antioxidant. Selenium is a co-factor of Glutathione peroxidase. Selenium has been reported to exert therapeutic effectiveness in pathologies where free radicals are the major cause. Studies have proved that selenium acts as a potent antioxidant for reverting free radical mediated damage in cancer condition (4). In this context, we seek to gain information about the possible role of selenium as an antioxidant in minimizing macromolecular damages and the interrelation between the deteriorative effect of free radicals on membrane structural integrity in the blood of oral squamous cell carcinoma (OSCC) patients.

\section{Materials and Methods}

\section{Study Design}

Oral cancer patients (Stage III) were taken into the study as approved by ethical committee (Ethical standards of Hospital Ethics committee on human experimentation (Permission letter No. 49541/E1/99-1, Department of Health, Directorate of Medical Education, India)).

The study was divided into 2 major groups, namely, Group I: Normal healthy individuals, $(n=45)$ Group II: Untreated oral cancer patients. $(n=63)$. Group II was further subdivided into Group IIa : Oral cancerpatients who have undergone radiotherapy $(n=27)$ and Group IIb: Oral cancer patients who have undergone radiotherapy and supplemented with selenium $(n=36)$. Both Group IIa and IIb were followed up for 6 months.
Treatment : Patients were treated by radical radiotherapy was delivered with a tele-cobalt beam using anterior and lateral wedge pair or lateral parallel portals (Theratron-780 $-{ }^{60} \mathrm{Co}$; phoenix $-{ }^{60} \mathrm{Co}$; Gammatron- ${ }^{60} \mathrm{Co}$ ) at a dosage of $6000 \mathrm{~Gy}$ (200 cGy/day) in five fractions per week for a period of six weeks. Selenium Supply: Selenium (Sodium selenite) capsules were supplied by the Cassel Research Laboratories (Chennai, India). Per capsule contained $400 \mathrm{~g}$ of selenium. Patients under the selenium group were given $400 \mathrm{~g}$ selenium/d for period of 6 months. Subjects were dispensed with selenium capsules at every month to ensure regular intake of the selenium capsules.

\section{Procedures}

Blood samples from all the groups were collected with EDTA. The level of lipid peroxides was assayed(5). Protein carbonyl content was determined(6). Free radicals were detected by electron spin resonance(7) using ESRSpectrometer JES-TE 200 ESR spectrometer (Japan electronics Datun Co., Osaka, Japan). DNA damage was assessed by using alkaline single cell gel electrophoresis (comet assay)(8). The extent of DNA-protein crosslinks was assayed(9). Agarose gel electrophoresis was carried out for the analysis of DNA fragmentation in the DNA of leucocytes..Apoptotic cells were enumerated by acridine orange and ethidium bromide, which stains the cell nuclei with modifications (10).

Erythrocyte membrane was isolated and modified (11). The level of membrane lipid peroxides was assessed (12). Aliquots of the reconstituted membrane preparation were taken for the assay of membrane- bound enzymes. Membrane bound $\mathrm{Na}^{+} \mathrm{K}^{+}$ATPase was assayed by the method of Bonting. $\mathrm{Ca}^{2+}$ and $\mathrm{Mg}^{2+}$ ATPase was estimated(13). Detailed procedure of the methods are published elsewhere.

\section{Statistical analysis}

Statistical significance of differences between all the groups were determined by students t-test . (The levels of significance were evaluated as $\mathrm{p}<0.001$ ). Values are expressed as mean \pm SD for each group. 
Int. J. Curr. Res. Med. Sci. (2016). 2(9): 8-21

Group II was compared with Group I. Group IIa patients were compared with Group II. Group IIb were compared with Group IIa to assess the efficacy of selenium supplementation.

\section{Results}

\section{Macro molecular damages}

A highly significant increase for plasma lipid peroxidation (Group II) was also observed in comparison to normals. Radiation group showed further increase in LPO by 14\% (2 months), $10 \%$ (4 months) and showed a non significant increase at 6 months (Figure 1). Interestingly, selenium supplementation significantly attenuated the plasma LPO levels by $23 \%$ for 2 months, $31 \%$ until 4 months and by 34\% for 6 months (Group II b1, b2, b3 compared with Group II a1, a2, a3) The levels of protein carbonyl in plasma of normal, untreated oral cancer, radiation treated and selenium supplemented groups (Figure 2). When compared with normal, increase in levels of protein carbonyls was observed in cancer patients by $131 \%$ (Group II). In radiation group, the carbonyl content increased significantly by $12 \%$ at 2 months and was found to be unaltered until 4 , 6 months on comparison with untreated oral cancer patients.

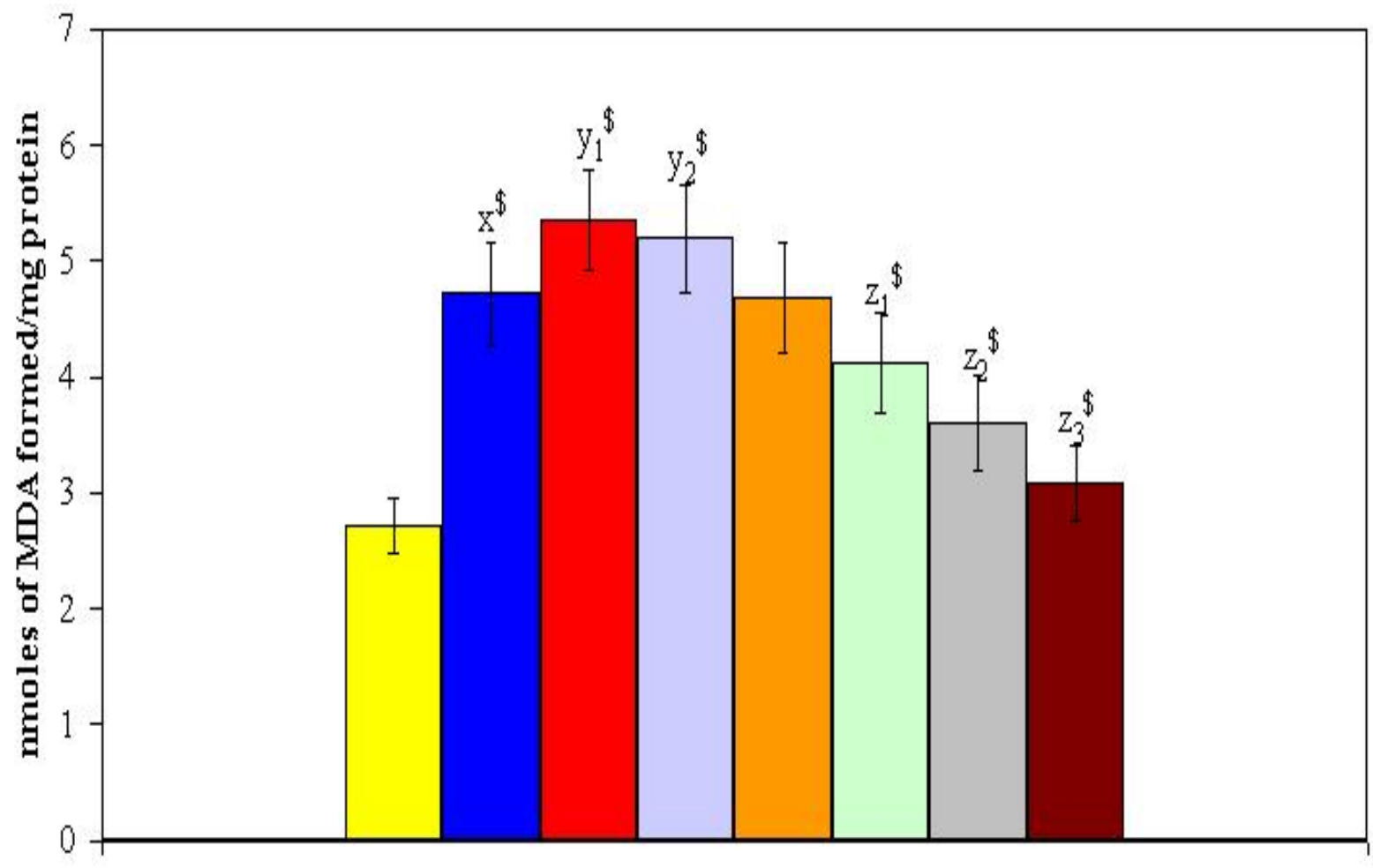

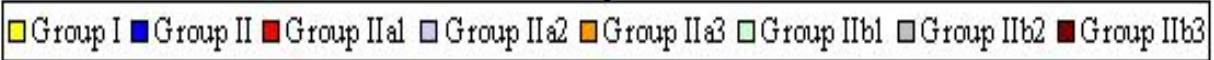

Figure 1: Levels of Plasma lipid peroxides in normal and study groups

Group I - Normal, Group II - Untreated oral cancer patients

Group II a1, a2, a3 - Radiation treated - 2, 4, 6 months respectively

Group II b1,b2,b3 - Radiation treated + selenium supplemented - 2,4,6 months respectively

Values are expressed as mean $\pm \mathrm{SD}$

${ }^{\mathrm{x}}$ Group II compared with Group I; ${ }_{1}^{\mathrm{y}}$ Group IIa1 compared with Group II; ${ }_{2}{ }_{2}$ Group IIa2 compared with Group II; ${ }_{3}$ Group IIa3 compared with Group II; ${ }_{1}$ Group IIb1 compared with Group IIa1; ${ }_{2}$ Group IIb2 compared with Group IIa2; ${ }_{3}^{\mathrm{G}}$ Group IIb3 compared with Group IIa3

Statistical significance are expressed as ${ }^{*} \mathrm{p} \quad 0.05 ;{ }^{\#} \mathrm{p} \quad 0.01 ;{ }^{\$} \mathrm{p} \quad 0.001$ 


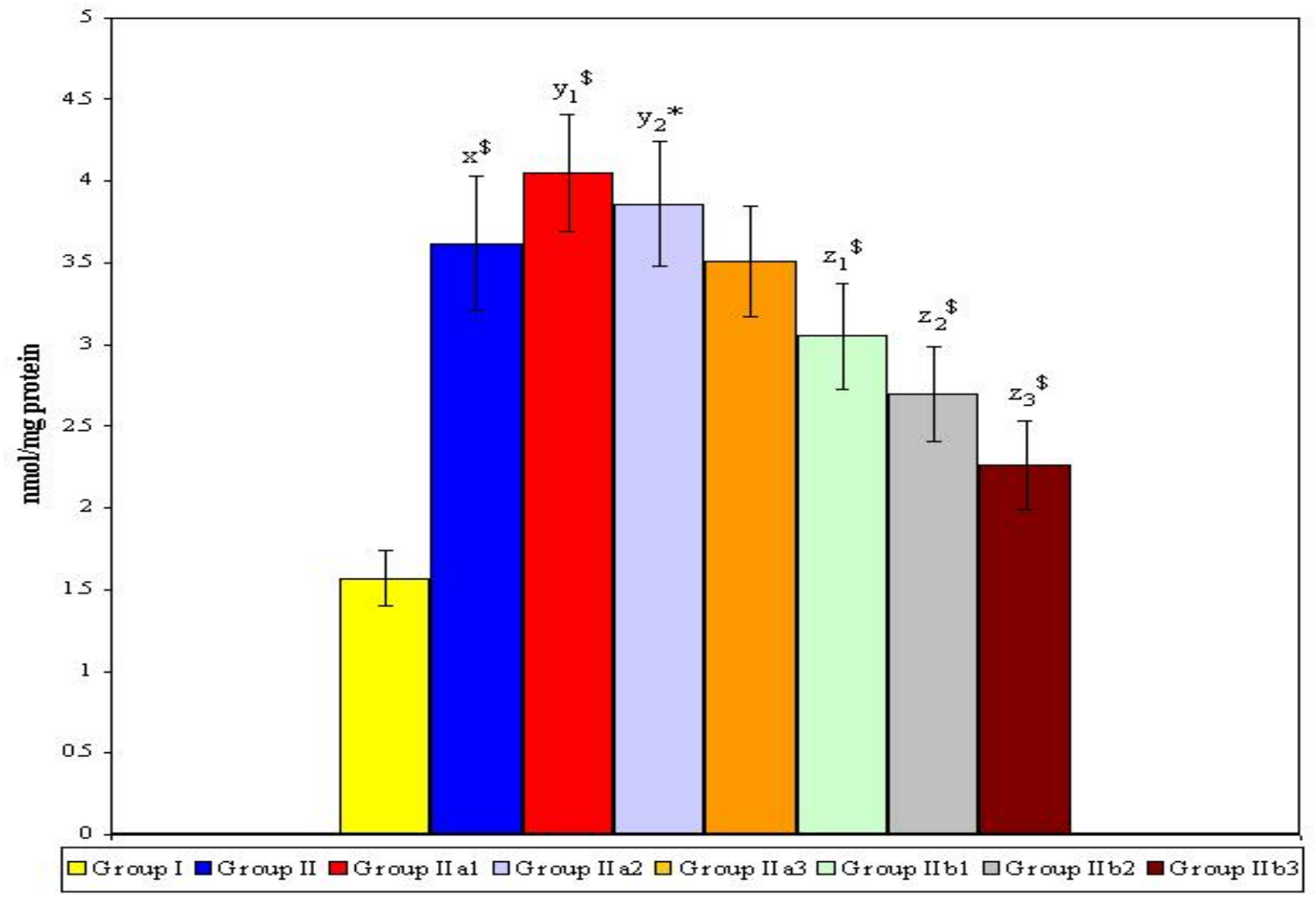

Figure 2: Plasma protein carbonylation in normal and study groups

Group I - Normal, Group II - Untreated oral cancer patients

Group II a1, a2, a3 - Radiation treated - 2,4,6 months respectively

Group II b1,b2,b3 - Radiation treated + selenium supplemented - 2,4,6 months respectively

Values are expressed as mean $\pm \mathrm{SD}$

${ }^{\mathrm{x}}$ Group II compared with Group I; ${ }_{1}^{\mathrm{y}}$ Group IIa1 compared with Group II; ${ }_{2}{ }_{2}$ Group IIa2 compared with Group II; ${ }_{3}$ Group IIa3 compared with Group II; ${ }_{1}^{\mathrm{z}}$ Group IIb1 compared with Group IIa1; ${ }_{2}^{\mathrm{z}}$ Group IIb2 compared with Group IIa2; ${ }_{3}^{2}$ Group IIb3 compared with Group IIa3

Statistical significance are expressed as ${ }^{*} \mathrm{p} \quad 0.05 ;{ }^{*} \mathrm{p} \quad 0.01 ;{ }^{\$} \mathrm{p} \quad 0.001$

The decline in the levels of protein carbonyls in the $2^{\text {nd }}, 4^{\text {th }}$ and $6^{\text {th }}$ month (Group II b1, b2, b3) following selenium supplementation in comparison to radiation groups (Group II a1, a2, a3) was found to be $25 \%, 30 \%, 36 \%$ respectively. (Figure 3) represents the DNA single strand breaks in leucocytes of normal, untreated oral cancer, radiation treated and selenium supplemented groups. (Figure 4) summarizes the level of DNA damage in leucocytes of normal, untreated oral cancer, radiation treated and selenium supplemented groups. Significant increase in single strand breaks were detected in leucocyte DNA of cancer patients by four fold in untreated cancer cases when compared with normal (Group II versus Group I) and also in radiation treated groups at 2, 4, 6 months (Group IIa1, a2, a3) compared with untreated oral cancer cases. The remarkable decrease in DNA-strand scissions by $23 \%, 34 \%$ and $41 \%$ for $2,4,6$ months was observed in selenium groups (Group II b1, b2, b3) when compared with radiation groups at 2, 4, 6 months respectively. Remarkable decrease of strand scissions was observed on long term selenium supplementation (Compare II b3 with II a3). 


\section{Normal}

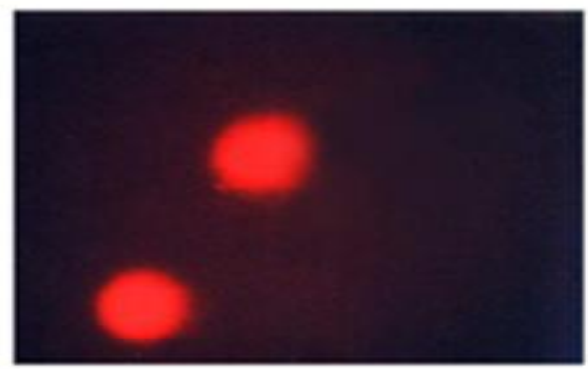

Radiation Treated

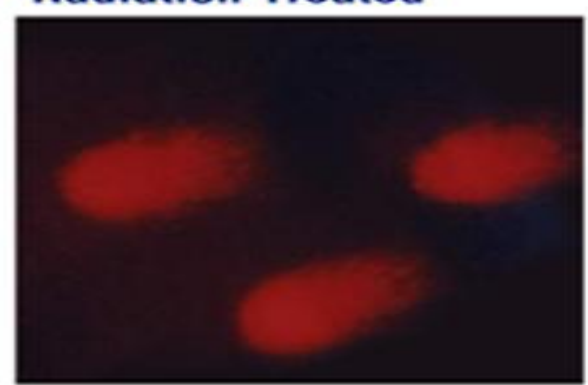

Untreated Oral Cancer [20x]

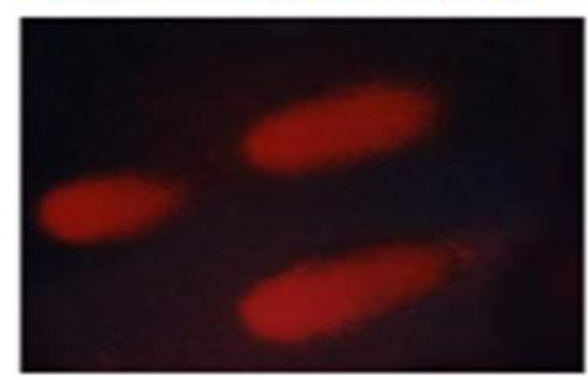

Radiation + Selenium Treated

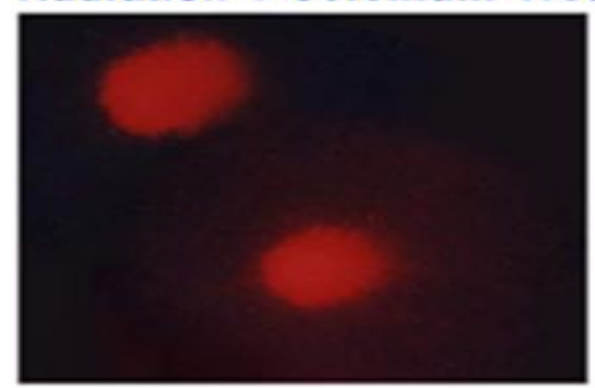

Figure 3: Leucocyte DNA-Strand breaks by Comet Assay in Normal and study groups

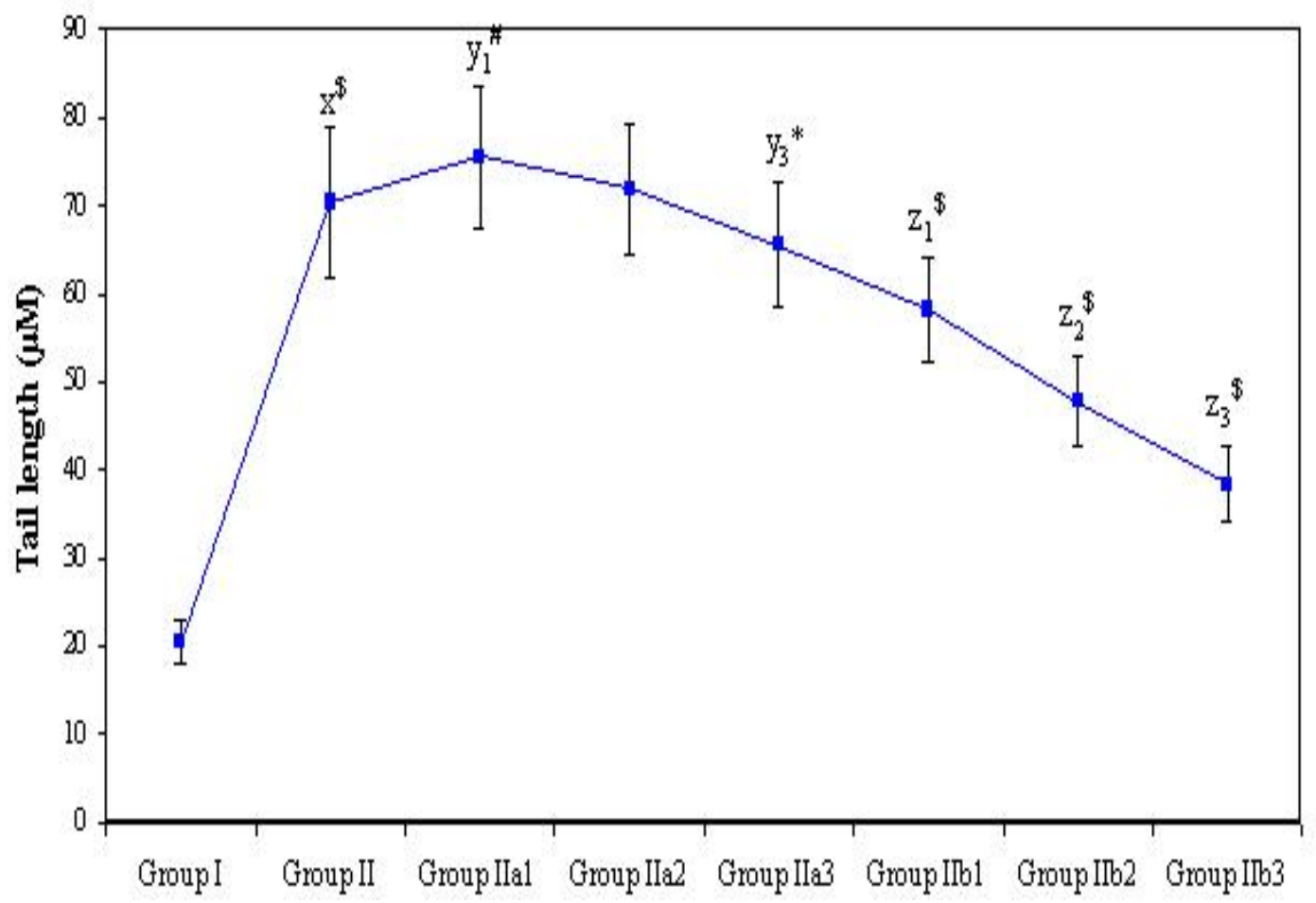

Figure 4: Distribution of DNA migration (Comet tail length) in normal and study groups

Group I - Normal, Group II - Untreated oral cancer patients

Group II a1, a2, a3 - Radiation treated - 2,4,6 months respectively

Group II b1, b2, b3 - Radiation treated + selenium supplemented - 2,4,6 months respectively

Values are expressed as mean $\pm \mathrm{SD}$

${ }^{\mathrm{X}}$ Group II compared with Group I; ${ }_{1}$ Group IIa1 compared with Group II; ${ }_{2}$ Group IIa2 compared with Group II; ${ }_{3}$ Group IIa3 compared with Group II; ${ }_{1}^{\mathrm{z}}$ Group IIb1 compared with Group IIa1; ${ }_{2}$ Group IIb2 compared with Group IIa2; ${ }_{3}$ Group IIb3 compared with Group IIa3

Statistical significance are expressed as ${ }^{*} \mathrm{p} \quad 0.05 ;{ }^{*} \mathrm{p} \quad 0.01 ;{ }^{\$} \mathrm{p} \quad 0.001$ 
Int. J. Curr. Res. Med. Sci. (2016). 2(9): 8-21

The level of DNA-protein cross links in leucocytes of normal, untreated oral cancer, radiation treated and selenium supplemented groups is depicted (Figure 5). Untreated oral cancer groups in comparison to normal showed threefold increase in the level of cross links (Group II). Radiation groups (Gp IIa1, a2, a3) showed a slight increase $(\mathrm{p}<.01)$ after 2 months while there was no significant increase in protein cross links at $4 \& 6$ months when compared with untreated oral cancer cases. Selenium treatment proved to be more effective in suppressing carcinogen induced and radiation induced cross links. The decrease in crosslinks increased with the selenium supplementation for 2,4 and 6 months by $17 \%, 33 \%, 45 \%$ respectively (Group II $\mathrm{b} 1, \mathrm{~b} 2, \mathrm{~b} 3)$ in comparison to radiation groups.

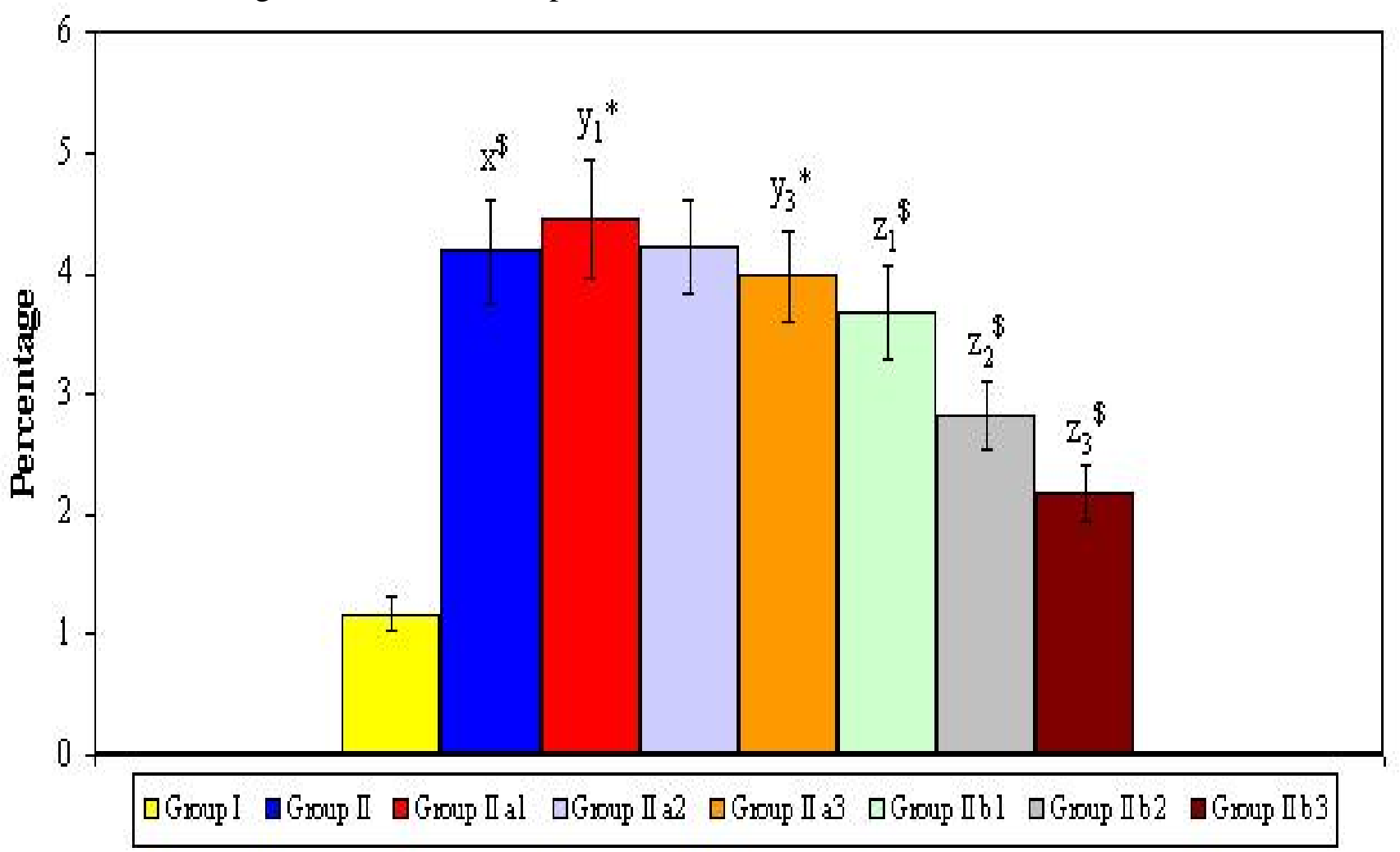

Figure 5: DNA-protein cross links levels in leucocytes of normal and study groups

Group I - Normal, Group II - Untreated oral cancer patients

Group II a1, a2, a3 - Radiation treated - 2,4,6 months respectively

Group II b1,b2,b3 - Radiation treated + selenium supplemented - 2,4,6 months respectively

Values are expressed as mean $\pm \mathrm{SD}$

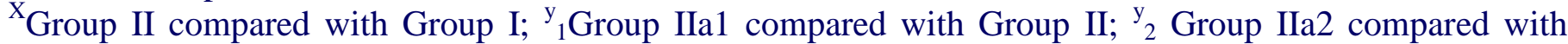
Group II; ${ }_{3}$ Group IIa3 compared with Group II; ${ }_{1}{ }_{1}$ Group IIb1 compared with Group IIa1; ${ }_{2}$ Group IIb2 compared with Group IIa2; ${ }_{3}$ Group IIb3 compared with Group IIa3

Statistical significance are expressed as $\stackrel{*}{\mathrm{p}} \quad 0.05 ;{ }^{\#} \mathrm{p} \quad 0.01 ;{ }^{\$} \mathrm{p} \quad 0.001$

\section{Apoptotic cascade}

Figure 6 depicts the DNA fragmentation from leucocytes of normal, untreated oral cancer, radiation treated and selenium supplemented groups. In (Group II) leucocyte DNA was found to be fragmented as evidenced by the DNA ladder formation upon agarose gel electrophoresis (lane 2). Typical fragmentation was observed in leucocyte of radiation group (group II a3) (lane 3), while selenium supplemented group had no ladder formation (group II b3 ) after 6 months (lane 4). 


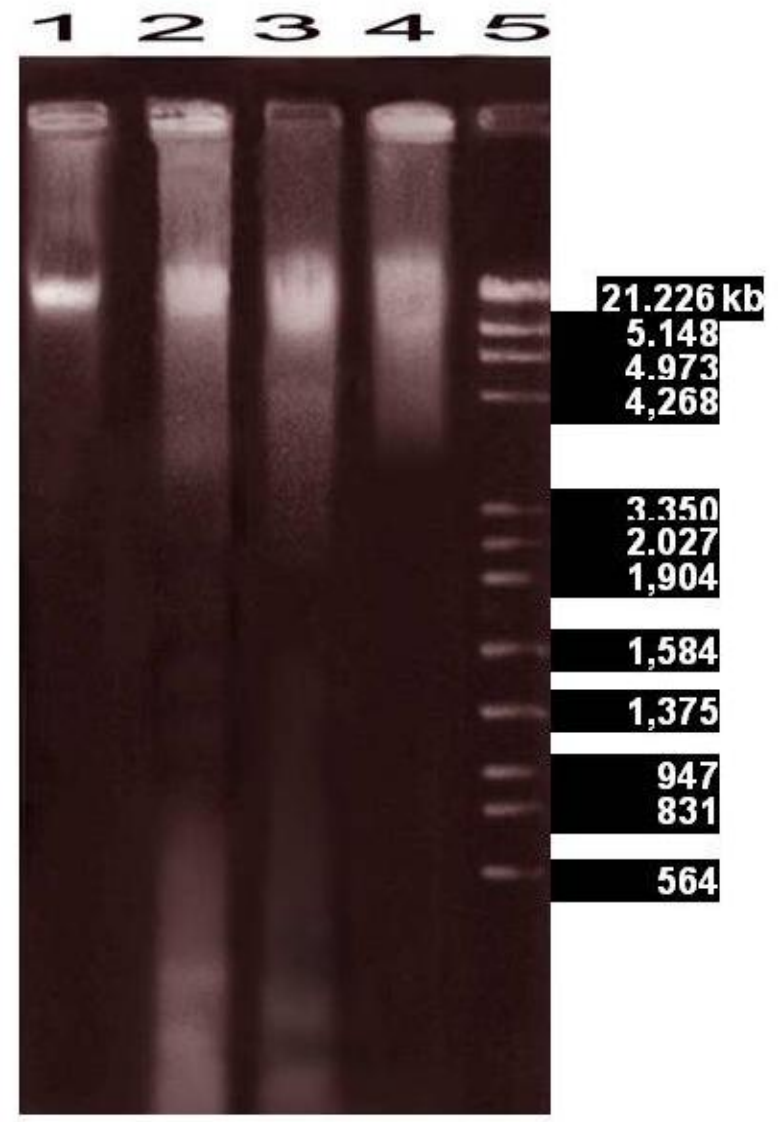

\section{Lane 1 - Normal \\ Lane 2 - Untreated oral Cancer \\ Lane 3 - Radiation Treated \\ Lane 4 - Radiation + Selenium Treated \\ Lane 5 - DNA marker [ $\lambda$-DNA/Hind III digest]}

Figure 6: Agarose gel electrophoretic pattern of leucocyte DNA in normal and study groups

Figure 7 exhibits the apoptotic index of the leucocytes and (Figure 8) represents the apoptotic cell death in leucocytes of normal, untreated oral cancer, radiation treated and selenium supplemented groups. Untreated cases (Group II) in comparison to normal showed seven fold increase in the amount of apoptotic bodies. When compared to untreated group this was found to be reduced by $27 \%$ following radiation after 6 months (Group II a3). Selenium supplemented group showed much more reduction by $43 \%$ $(\mathrm{P}<0.001)$ in apoptotic bodies (GroupII b3 compared with Group II a3). 
Int. J. Curr. Res. Med. Sci. (2016). 2(9): 8-21

Normal

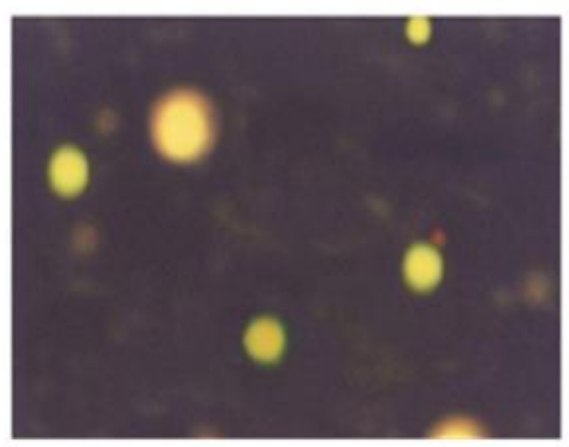

Radiation Treated

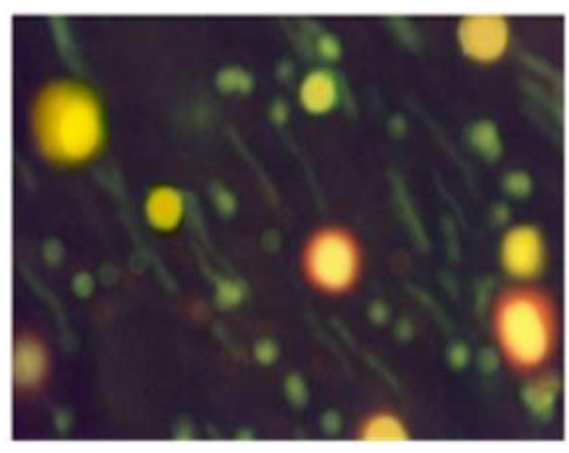

Untreated Oral Cancer

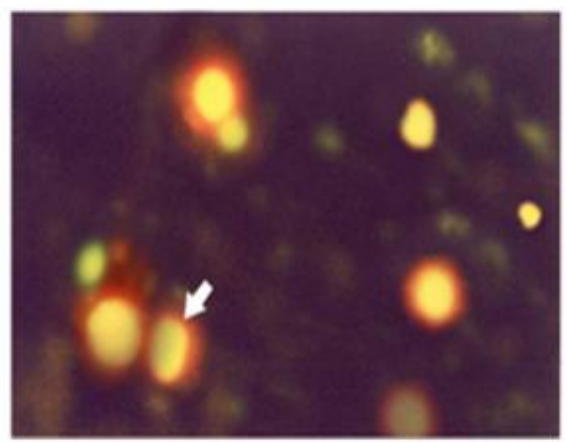

Radiation + Selenium Treated

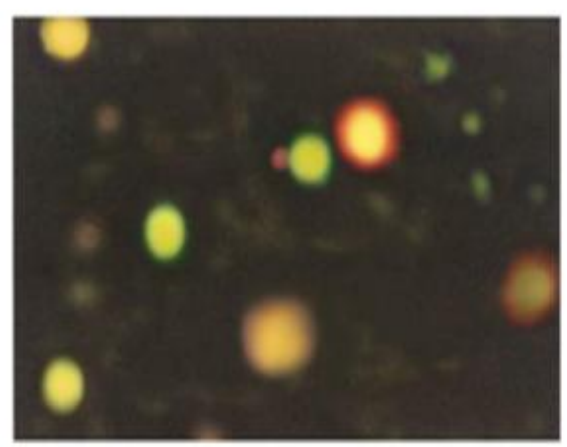

Figure 7: Apoptotic cell death in leucocyte nuclei of normal and study groups

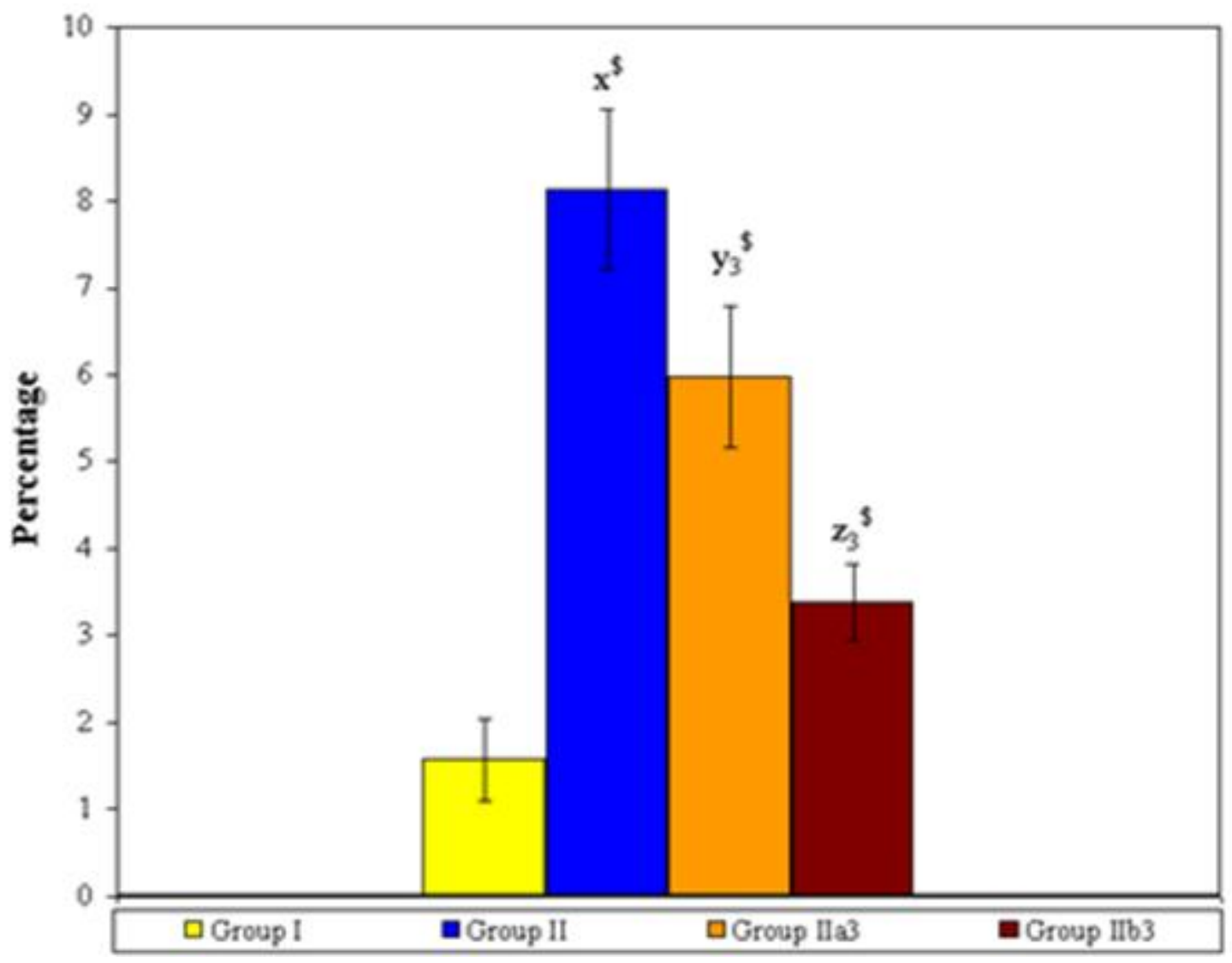

Figure 8: percentage of apoptosis in leucocytes of normal and study groups 


\section{Effect over Membrane structural integrity}

Figure 9 shows the free radical levels in erythrocyte, erythrocyte membrane of normal, oral cancer patients, radiation treated and selenium supplemented groups. Free radical levels appeared to be remarkably enhanced as evidenced with the increased spin concentration denoting over production of reactive oxygen species during carcinogen metabolism in untreated oral cancer patients. Several fold increase in free radical levels was observed in erythrocyte and erythrocyte membrane of untreated oral cancer patients (Group II). Free radical levels increase by $28 \%, 12 \%$ for 2 months and non significant increase for 6 months was observed in erythrocyte and erythrocyte membrane of radiation treated group when compared with oral cancer patients (Compare Group II a1, a2, a3 with Group II). Selenium reduced the free radical content in erythrocyte and erythrocyte membrane by $37 \%$ and $24 \%$ for 2 months, $34 \%$ and $35 \%$ for 4 months and around $45 \%$ for 6 months respectively when compared with 2, 4 and 6 months of radiation treated group. Based on the results showing high significance at 6 months, the studies below were carried out only on 6 months follow up of radiation and selenium supplemented groups (Group II a3 and Group II b3).Comparison of lipid peroxidation in membrane of oral cancer patients with and without selenium supplementation (data not shown) showed typical results as that of plasma LPO. Selenium administration for 6 months brought down the level of membrane lipid peroxides significantly in the oral cancer patients of Group IIb in comparison to untreated and radiation treated patients, Group IIa $(\mathrm{P}<0.05)$.

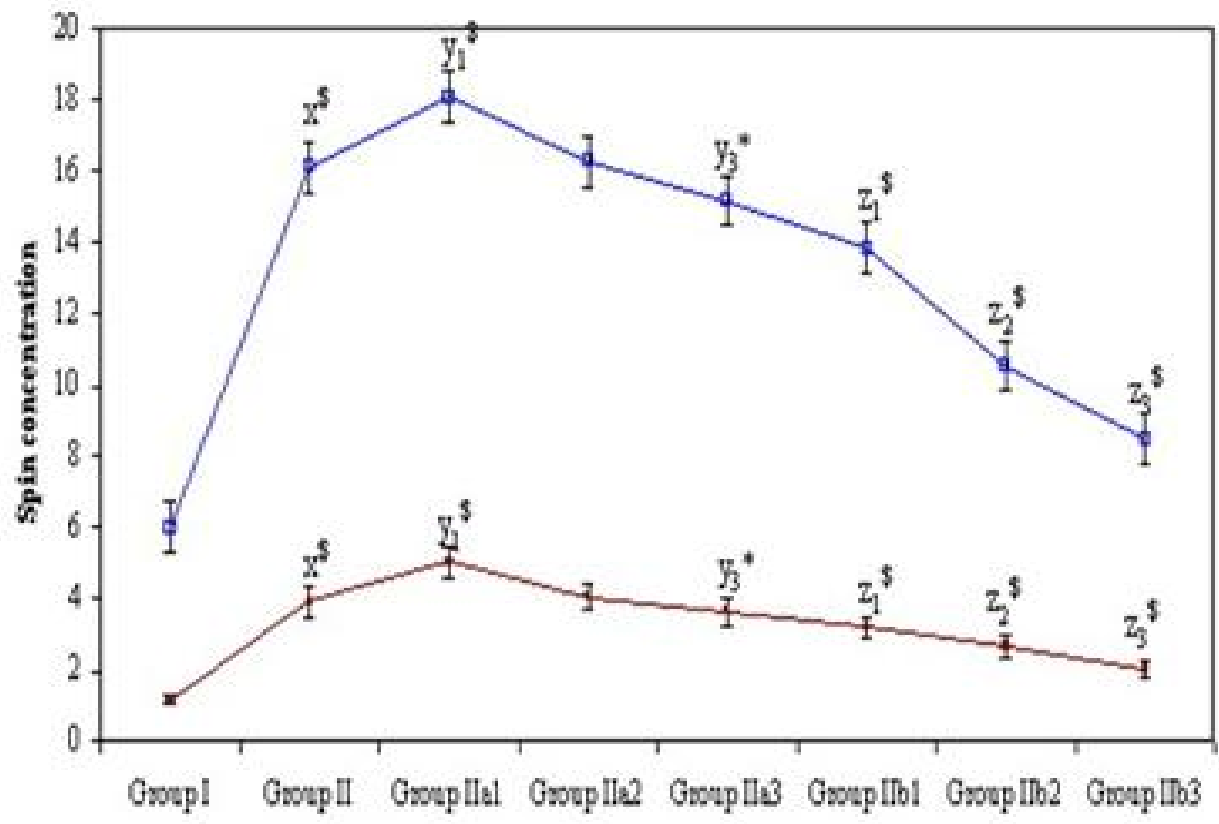

-Erthrocyte - Exythrocys metubare

Figure 9; Free radical levels in erythrocyte, erythrocyte membrane in normal and study groups

Group I - Normal, Group II - Untreated oral cancer patients

Group II a1, a2, a3 - Radiation treated - 2,4,6 months respectively

Group II b1,b2,b3 - Radiation treated + selenium supplemented - 2,4,6 months respectively

Values are expressed as mean \pm SD

${ }^{\mathrm{X}}$ Group II compared with Group I; ${ }_{1}$ Group IIa1 compared with Group II; ${ }_{2}$ Group IIa2 compared with Group II; ${ }_{3}$ Group IIa3 compared with Group II; ${ }_{1}^{\mathrm{z}}$ Group IIb1 compared with Group IIa1; ${ }_{2}$ Group IIb2 compared with Group IIa2; ${ }_{3}$ Group IIb3 compared with Group IIa3

Statistical significance are expressed as ${ }^{*} \mathrm{p} \quad 0.05 ;{ }^{*} \mathrm{p} \quad 0.01 ;{ }^{\$} \mathrm{p} \quad 0.001$ 
Table 1 illustrates the activities of erythrocyte membrane bound ATPases $\left(\mathrm{Na}^{+} \mathrm{K}^{+}, \mathrm{Mg}^{2+}, \mathrm{Ca}^{2+}\right)$ of normal, untreated oral cancer, radiation treated and selenium supplemented groups. Compared with normal (Group I) minimal activation of $\mathrm{Na}^{+} \mathrm{K}^{+}$ATPase was noticed in cancer patients (Group II) (P < 0.001). Slightly increased activation of $\mathrm{Na}^{+} \mathrm{K}^{+}$ATPases was seen with radio therapy group at 6 months $(\mathrm{p}<0.05)$ (Group IIa compared with Group II). Maximal activation of $\mathrm{Na}^{+} \mathrm{K}^{+}$ ATPase was seen in selenium-supplemented group after 6 months $(\mathrm{P}<0.001)$ (Group IIb versus Group IIa). $\mathrm{Mg}^{2+}$ ATPase activity was significantly lowered in Group II than in Group I $(\mathrm{p}<0.001)$.
Mild increase in $\mathrm{Mg}^{2+}$ ATPase in Group IIa was observed in comparison to Group II $(\mathrm{p}<0.05)$. However, selenium supplemented group (Group IIb versus Group IIa) showed moderate increase in $\mathrm{Mg}^{2+}$ ATPase activity $(\mathrm{p}<0.001)$. There was a significant decrease in $\mathrm{Ca}^{2+}$ ATPase in untreated OSCC compared to normal ( $p<0.001)$ (Group II vs Group I). Though radiation treated patients of Group IIa showed little increase of $\mathrm{Ca}^{2+}$ ATPase $(p<0.05)$ than Group II comprising of untreated oral cancer patients, a significant increase was noticed following selenium supplementation Group IIb $(\mathrm{p}<0.001)$ when compared to Group IIa.

Table 1: Activities of $\mathrm{Na}^{+} \mathrm{K}^{+}, \mathrm{Ca}^{2+}, \mathrm{Mg}^{2+}$ ATPases in erythrocyte membrane of normal, untreated oral cancer, radiation treated and radiation treated + selenium supplemented oral cancer patients

\begin{tabular}{|c|c|c|c|c|}
\hline & \multirow{2}{*}{$\begin{array}{c}\text { Normal } \\
\text { (Group I) }\end{array}$} & \multirow{2}{*}{$\begin{array}{l}\text { Untreated } \\
\text { Oral Cancer } \\
\text { (Group II) }\end{array}$} & Radiotherapy alone & $\begin{array}{c}\text { Radiotherapy }+ \\
\text { Selenium } \\
\text { supplemented groups }\end{array}$ \\
\hline & & & $\begin{array}{c}6 \text { months } \\
\text { (Group II a })\end{array}$ & $\begin{array}{c}6 \text { months } \\
\left(\text { Group II b } b_{3}\right)\end{array}$ \\
\hline $\mathrm{Na}^{+} \mathrm{K}^{+}$ATPase & $0.557 \pm 0.061$ & $0.387 \pm 0.038^{\mathrm{x} \$}$ & $0.412 \pm 0.041_{3}^{\mathrm{y}}{ }^{*}$ & $0.451 \pm 0.042^{\mathrm{z}}{ }_{3}^{\#}$ \\
\hline $\mathrm{Ca}^{2+}$ ATPase & $0.252 \pm 0.023$ & $0.187 \pm 0.019^{\mathrm{x} \$}$ & $0.2 \pm 0.021_{3}^{\mathrm{y}}{ }^{*}$ & $0.221 \pm 0.021_{3}^{\mathrm{z}}$ \\
\hline $\mathrm{Mg}^{2+}$ ATPase & $0.781 \pm 0.081$ & $0.533 \pm 0.056^{\mathrm{x} \$}$ & $0.570 \pm 0.057^{\mathrm{y}}{ }_{3}^{*}$ & $0.683 \pm 0.086_{3}^{\mathrm{z}}$ \\
\hline
\end{tabular}

$\mathrm{Na}^{+} \mathrm{K}^{+}$ATPase, $\mathrm{Ca}^{2+}, \mathrm{Mg}^{2+}$ ATPases - moles of pi liberated/mg protein/min

Group I - Normal; Group II - Untreated oral cancer patients; Group I a3 - Radiation treated - 6 months Group II b3 - Radiation treated + selenium supplemented - 6 months

Values are expressed as mean $\pm \mathrm{SD}$

x -Group II compared with Group I; $\quad$ y $_{3}$ Group IIa1, IIa2, IIa3 compared with Group II

$\mathrm{z}_{3}$ - Group IIb3 compared with Group IIa3.

Statistical significance are expressed as $* \mathrm{p}<0.05 ;{ }^{*} \mathrm{p}<0.01 ;{ }^{\$} \mathrm{p}<0.001$

\section{Discussion}

\section{Macromolecular damages}

\section{Free radicals and Lipid peroxidation}

A higher level of LPO in plasma of oral cancer patients might be due to iron dependent ROS generation for antioxidant system which could ultimately degrade the PUFA of the biomembrane. Radiation toxicities cause antioxidant enzyme deficiencies in the erythrocyte of radiation treated oral cancer patients which may render the defense system inefficient to manage free radical attack Erythrocytes are continuously exposed to oxidative stress when subjected to radiation(14). Although the reducing capacity of the normal erythrocyte is greater than its oxidizing potential, the lack of antioxidants might have led to an increase in membrane LPO during the study. In the present study, selenium supplemented groups showed diminished levels of LPO, which could be attributed to the metal chelating $^{24}$ and antioxidative and antiapoptotic property(15) of selenium. 
Epidemiological studies have demonstrated a clear causal association between oxidative stress and increased risk for oral cancer. The increased free radical content might be due to pro oxidant and antioxidant imbalance in oral cancer cases,(16) . The primary event for radiation induced reactions in membrane is a result of the oxidative damage of membrane protein bound $\mathrm{SH}$ to disulfides and its consequent alterations in protein metabolism(17). Diminished levels of free radicals might be related to the free radical scavenging and antioxidant enhancing property of selenium. Since selenium is endowed with favourable capacity to enter into erythrocytes via diffusion(18), high retention of it, might contribute to elimination of free radicals.

\section{Protein oxidation}

ROS-mediated reactions lead to the formation of protein carbonyl groups which serves as a molecular indicator of cancer(19). In the present finding, protein carbonyl levels increased markedly in the cancer and radiation treated patients. This may be attributed to accumulation of oxidatively damaged proteins reflecting increased rate of ROS generation. Oxidatively damaged protein is known to compromise the mechanisms of cellular regulation and signal transduction. On supplementation of selenium (Group II b1, b2, b3) for 2, 4 and 6 months, a maximum decrease in protein carbonyls owed to the property of selenium to decrease free radical production and thereby decrease protein oxidation.

\section{DNA Damage}

Most mutagens and carcinogens are thought to induce genetic changes by interacting with DNA(20). In the present study, the DNA strand breaks was found to be high in leukocytes of oral cancer cases as well as in radiation cases may be due to increased generation of $\mathrm{H}_{2} \mathrm{O}_{2}$, as well as inefficient DNA repairing capacity associated in the inactivation of DNA polymers. DNA strand breaks, which are produced by direct interaction of the hydroxyl radical $\left(\mathrm{OH}^{\circ}\right)$ with chromatin can be noted in cancer associated cellular and physiological processes(21). Inefficient DNA repairing capacity enhanced damage to the DNA in radiation treated cancer patients. Selenium treated group decreased DNA strand breaks possibly by (i) reducing the breakage of chemical bonds that occurs during ionization, (ii) preventing the interaction of free radicals with the macromolecule and (iii) providing support to the repair mechanism of DNA. Selenium protects against carcinogen induced chromosomal damage by enhancing the DNA repair process(22).

\section{DNA - Protein Crosslinks}

The cross-linking of certain amino acids present in proteins to DNA may be attributed to the increased DNA-protein cross-links. Ionising radiation and free radicals have been shown to cross-link certain amino acids (23). Selenium greatly decreased the DNA-protein crosslinks, indicating the role of selenium in declining the oxidative attack over DNA suggest that oxidative DNA damage resulting from endogenous free radical attack, contributes to the etiology of cancer and selenium might thus reduce the interaction of vicinal free radicals on DNA strand and adjacent protein and confer protection against cancer.

\section{Apoptotic Cascade}

DNA fragmentation profile was observed in the leucocyte of oral cancer and radiation treated cases might be attributed to the enhanced activity of caspase-3. Administration of selenium reduced DNA fragmentation of blood leucocytes than radiation treated oral cancer cases. Following selenium administration apoptotic cell count decreased to greater extent. On selenium supplementation a decrease in apoptotic count was observed which indicates the radical scavenging action of the antioxidant selenium through suppression of TNF- $\alpha$.

\section{Membrane structural integrity}

Membrane lipids succumb easily to the devastating actions of reactive oxygen species. Lipid peroxidation initiates the disruption of membrane fluidity facilitating the leakage of $\mathrm{Ca}^{2+}$ ions into the cell and thereby potentiate extensive membrane 
damage. Selenium, an antioxidant mineral is endowed with favorable capacity to pass through membranes, enter into erythrocytes via diffusion (24), therefore high retention of it, might contribute to the elimination of free radicals. Thus it protects cells against oxidative stress caused by ROS by substantial reduction in LPO products scavenging the debilitating consequences of free radicals. This may also be attributed to the favorable capacity of the antioxidant mineral to directly reduce GSSG to $\mathrm{GSH}$ and maintain its ratio(25).

A decline in $\mathrm{Na}^{+} \mathrm{K}^{+}$ATPase, $\mathrm{Ca}^{2+}$ ATPase and $\mathrm{Mg}^{2+}$ ATPase activities observed in oral cancer and radiation treated groups denote oxidative assault and increased level of lipid peroxidation. This is attributed to the leakage of $\mathrm{K}^{+}$ions into the extra cellular medium. The disruption of membrane permeability and fragmentation of the membrane leads to increased $\mathrm{Ca}^{2+}$ level in the intracellular compartment. This may in turn affect ionic channels and thiol-dependent membranebound enzymes and that's how the net transport of ions by $\mathrm{Mg}^{2+}$ ATPase associated with the hydrolysis of ATP is hindered .

Selenium compounds can act as free radical traps, scavenging it and converting them to stable products. By preventing leakage of $\mathrm{Ca}^{2+}$ ions into the cell, Selenium exhibited a significant cytoprotective effect against an increase of cytosolic free calcium caused by peroxides. It may exert scavenging action, to preserve the ATPase enzyme activity by increasing membrane - SH content. Administration of selenium increases GPx synthesis by enhancing de novo synthesis of this enzyme in the erythroid precursors of red blood cells(26). Therefore the multifold increase in GPx activity on selenium treatment may be the reason for decreased oxidative stress which in turn there is enhancement in the activities of ATPases. Administration of selenium might have protected membrane lipids from peroxidation and thereby prevent the loss of various ATPase activities(27) through its antioxidant property, and thereby maintain stabilization of cell membrane integrity .

\section{Conclusion}

The imbalance in cellular redox status in oral cancer patients undergoing radiotherapy resulted in the functional impairment of the normal cells. Abundant free radical generation during radiotherapy go hand in hand with cancer mediated radical generation which is furthermore debilitating and at times overwhelming. In this point of view the study results show that selenium may represent a form of controlling macromolecular damages and offer protection to cell membrane by eliminating free radicals. So there is a clinical interest for cancer patients undergoing radiation treatment to have this selenium supplementation. Further studies indepth are required to understand the usage of other selenium compounds too.

\section{Acknowledgements}

The author acknowledges the financial assistance rendered by the Division of Research Funds, University of Suwon, S Korea, for to undergo this research study.

\section{Conflict of Interest}

Authors declare no conflict of interest. The authors state no conflict of interest.

\section{References}

1. Azzam EI, Jay-Gerin JP, Debkumar Pain D. Ionizing radiation-induced metabolic oxidative stress and prolonged cell injury. Cancer Lett 2012; 327: 48-60.

2. Koukourakis MI. Radiation damage and radioprotectants: new concepts in the era of molecular medicine. Br J Radiol 2012; 85: 313-330.

3. Halliwell B, Gutteridge JML In. Production of Hydroxyl Radicals in living systems. Free Radicals in Biology and medicine. Oxford: Clarendon press, 1989. P. 300 - 56. 
4. Patrick Lyn. Selenium Bio-Chemistry and Cancer; A review of the literature. Alternative Medicine Review 2004; 9: 239-258.

5.. Ohkawa H, Ohishi N, Yogi K. Assay : for lipid peroxides in animal tissues by thio barbituric acid reaction. Anal Biochem 1979; 95: 351-358.

6. Levine RL, Williams JA, Stadtman ER, Schacter E. Carbonyl assays for determination of oxidatively modified proteins. Methods Enzymol 1994; 233:346-357.

7. Lohmann W, Schreiber J, Strobelt W, MullerEckhardt C. On the possible involvement of ascorbic acid and copper proteins in leukemia: I.Electron spin resonance (ESR) investigation on native blood erythrocytes and leukocytes. Bulletin 1979; 39 : 317-326.

8. Singh NP, McCoy MT, Tice RR and Schneider EL. A simple technique for quantitation of low levels of DNA damage damage in individual cells. Exp Cell Res 1988; 175: $184-191$.

9. Zhitkovich A , Costa M . A simple, sensitive assay to detect DNA-protein crosslinks in intact cells and in vivo. Carcinogenesis 1992; 13: 1485 -1489 .

10. Liles WC, Kienes PA, Ledbetter JA, Aruffo A, Klebaroff SJ. Differential expression of Fas(CD95) and fas ligand on normal human phagocytes : Implications for the regulation of apoptosis in neutrophils. J. Exp. Med 1996; 184 : 429-440.

11. Quist EM. Regulation of erythrocyte membrane shape by calcium ion. Biochim Biophys Acta 1980;92: 631-637.

12. Ohkawa H, Ohishi N, Yogi K. Assay : for lipid peroxides in animal tissues by thio barbituric acid reaction. Anal Biochem 1979;95: 351-358.

13. Ohinishi T, Suzuki T, Suzuki Y, Ozawa K. A comparative study of plasma membrane magnesium ion ATPase activities in normal regenerating and malignant cells. Biochim Biophys Acta 1982; 634: 67-74.

14. olters H , Konings AWT . Radiation effects of Membranes Radiation research 1982; 92 : 474 482

15. Sonaa .E, Usha. S , Ja In J. An ex vivo study of selenium, Genistein on themorphological and nuclear changes in anticancer drugs induced apoptotic human peripheral lymphocytes. Bio Factors, 2013; 39: 279-293.
16. Rumley AG, Paterson JR . Analytical aspects of antioxidants and free radical activity in clinical biochemistry. Ann Clin Biochem 1998; 35: 181200.

17. Verma, Rastogi A. Rad Research 1990;122 : 130-136.

18. Boylan M , Spallholz JE. Selenium. In : Sports nutrition vitamins and trace minerals. Wolisnky I and Driskall JA, editors. CRC Press, New York, 1997; p. 195-204.

19. Marangon K, Devaraj S, Jialal I . Measurement of protein carbonyls in plasma of smokers and in oxidized LDL by an ELISA. Clinical chemistry 1999; 45 : 23-28.

20. Alisson M.De, Gontijo MC, Elias FN, Salvadori DMF, Luiza M, Oliverisa, et al. Single - Cell Gel (Comet) Assay Detects primary DNA damage in Non neoplastic Urothetical cells of prolcers and Ex-smokers. Cancer Epidemiology, Bio Markers and prevention 2001; $10: 987-933$.

21. Duthie SJ, Aiguo Ma, Marion A. Ross , Andrew R.Collins. Antioxidant supplementation decreases oxidative DNA damage in Human lymphocytes. Cancer Res 1996; 56 : 1291-1295.

22.Bera S, De Rosa V, Rachidi W. Does a role for selenium in DNA damage repair explain apparent controversies in its use in chemoprevention? Mutagenesis 2013; 28: 127134.

23. Fairbaim DW, Olive PL, Neill KLO. The Comet assay: A comprehensive review. Mutation Research1995;339 : 37-59

24. Boylan M, Spallholz JE. Selenium. In : Sports nutrition vitamins and trace minerals. Wolisnky I and Driskall JA, editors. CRC Press, New York,1997. p.195-204

25. Mahmoud KZ, Edens FW. Influence of organic selenium on hsp70 response of heatstressed and enteropathogenic Escherichia colichallenged broiler chickens (Gallus gallus).Comp Biochem Physiol C Toxicol Pharmacol 2005; 141:69-75.

26. Sen CK. Nutritional BioChemistry of Cellular glutathione. Nutritional BioChem 1997; 8:660-672. 
Int. J. Curr. Res. Med. Sci. (2016). 2(9): 8-21

27. Cay M, Naziroglu M. Effects of intraperitoneal-administered vitamin $\mathrm{E}$ and selenium on the blood biochemical and hematological parameters in rats. Cell Biochem and Function 1999; 17: 143-148.

\begin{tabular}{|c|c|}
\hline \multicolumn{2}{|c|}{ Access this Article in Online } \\
\hline \multirow{2}{*}{ 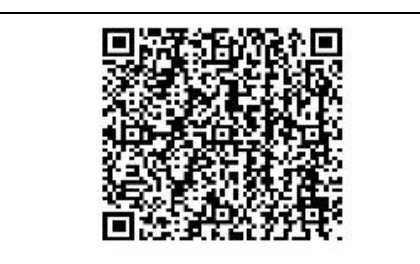 } & $\begin{array}{l}\text { Website: } \\
\text { www.ijcrims.com }\end{array}$ \\
\hline & \multirow[t]{2}{*}{$\begin{array}{l}\text { Subject: } \\
\text { Oncology }\end{array}$} \\
\hline Quick Response Code & \\
\hline$: 10$. & 5.02 .09 .002 \\
\hline
\end{tabular}

\section{How to cite this article:}

Sonaa Elango, Zenith Khashim, Shila Samuel, Usha Subbiah, Marie Carmel Balcos. (2016). Modulation of macromolecular damages and membrane structural integrity by Selenium in Radiation treated human stage (III) oral cancer cases. Int. J. Curr. Res. Med. Sci. 2(9): 8-21.

DOI: http://dx.doi.org/10.22192/ijcrms.2016.02.09.002 